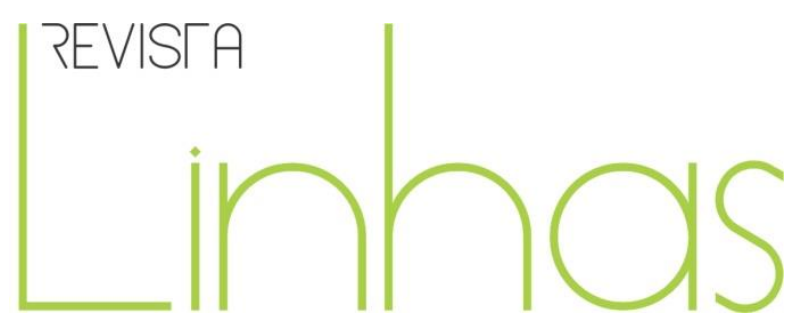

\title{
Entre as águas do cotidiano: movimento, espanto e encantamento
}

\section{Resenha do livro "Aquela água toda"}

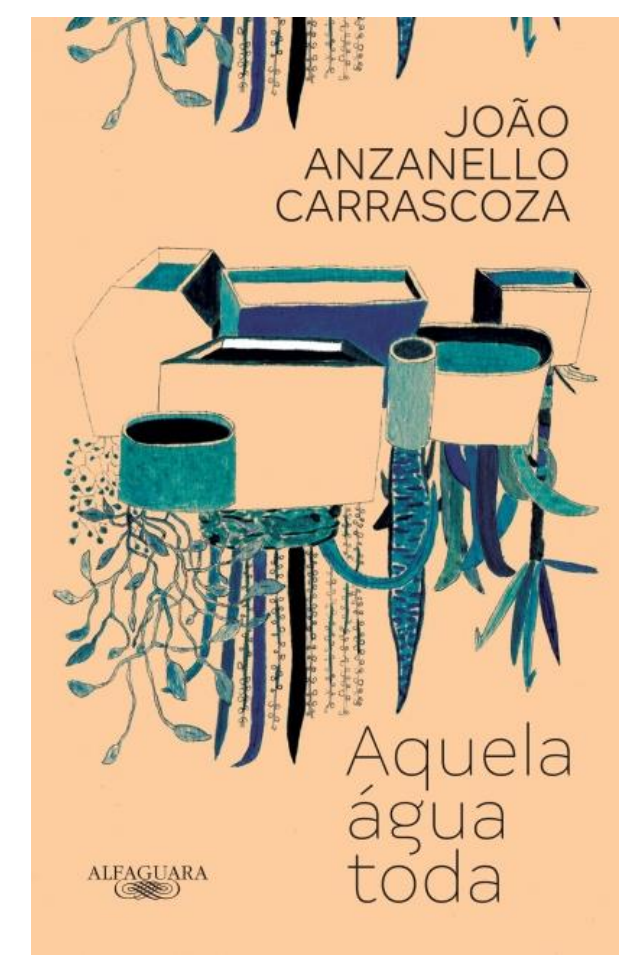

CARRASCOZA, João Anzanello. Aquela água toda. $1^{\text {a }}$ edição. Rio de Janeiro: Alfaguara, 2018. 112p.

\section{Cristiane Guimarães}

Universidade Federal de Santa Catarina - UFSC - Florianópolis/SC - Brasil

Rede Municipal de Educação de Florianópolis/SC - Brasil

turmasdacris@gmail.com

\section{Para citar esta resenha:}

GUIMARÃES, Cristiane. Resenha do livro "Aquela água toda". Revista Linhas. Florianópolis, v. 22, n. 50, p. 364-370, set./dez. 2021. 
Durante os processos de leitura e estudo do doutorado', encantei-me com a literatura do escritor João Anzanello Carrascoza. E em consonância com o encantamento, o desejo de compartilhar com outras pessoas as delicadezas de suas narrativas aconteceu quase naturalmente. Como um rio querendo desaguar, como o autor mesmo conta em suas prosas sobre a vida.

Inicialmente escrevi sobre Aos 7 e aos 40, um belíssimo livro relançado em 2018 e que foi muito importante na definição de caminhos de minha pesquisa, que buscou, entre outras reflexões, afirmar a importância da vida na escola e como a vida reluz nos encontros escolares em muitas linguagens diversas, especialmente nos textos escritos dos estudantes. No livro, percebi o belo encontro de tempos que dançam em nossas subjetividades, nos compondo e recompondo nas estações da vida. É um brilho que reluz nas menores coisas.

Por isso, proponho-me, novamente, a compartilhar um escrito do autor porque, em sua literatura, leio uma beleza que sempre procurei cultivar em minhas aulas como professora de Língua Portuguesa: construir a relação daquilo que lemos e estudamos com a vida, com a nossa vida, com a nossa formação, com a reinvenção de uma humanidade possível, com o que de melhor e de não tão melhor temos a compartilhar, a aprender ou reaprender. Ler o mundo para ler as palavras. Ler as palavras para ler de modo diferente o mundo, como nos ensinou Paulo Freire (1989, 2015).

O livro Aquela água toda, lançado em 2012 pela CosacNaify, reeditado pela Alfaguara em 2018, reúne 11 narrativas cujos enredos, leves e envolventes, nos dão uma lição sobre a preciosidade guardada nos baús dos silenciosos cotidianos do mundo e da vida. É um livro de instantes e de muitas águas em movimento. De instantes que tecem uma vida inteira, como escreve Bachelard (1994), e das águas que vêm sugerir a dança do tempo: “O tempo em ondas, ele só percebia que o tempo era o que era quando já passara, misturando-se a outras águas." (CARRASCOZA, 2018, p. 12).

Alguns desses instantes são ressignificados nas belas ilustrações produzidas por Rodrigo Visca. Carrascoza (2020), ao comentar a primeira edição da obra, em entrevista ao

\footnotetext{
${ }^{1}$ A pesquisa Poéticas da vida na escola: um inventário de memórias e afetos, foi defendida no Programa de Pós-graduação em Educação, na Universidade Federal de Santa Catarina, com orientação do Prof. Dr. Leandro Belinaso Guimarães.
} 
LABPUB, afirma ter percebido desde então a importância de, juntamente às editoras, dar atenção à harmonia entre texto e imagem nas composições gráficas. A edição de 2012 deu ao autor prêmios importantes e presença na FLIP - Festa Literária Internacional de Paraty - daquele ano. E porque os contos se mantêm tão atuais e fulgurantes me encantei com os momentos narrados, daí que eles seguiram em conversas preciosas com a pesquisa.

As cenas desenhadas com as palavras por Carrascoza (2018) são marcantes e se abrem à potência de um cotidiano outro, reinventado nas belezas de cada personagem, no ângulo da câmera de cada narrador, nas levezas e cruezas esboçadas nas narrativas. Nas águas que nos tomam e também naquelas que não domamos: "Ignorava que a vida tinha sua própria maré" (CARRASCOZA, 2018, p. 11).

A pesquisadora Michele Petit (2013), em suas considerações sobre a importância da leitura, conta que, ao longo da vida, há fragmentos de textos e de leituras que realizamos e que vão nutrindo nossa voz e nossa autoria de vida. Os contos de Carrascoza (2018) neste livro nos presenteiam com muitas passagens assim: caminhos que nos tomam, inundandonos com suas águas. Cenas poéticas lidas com os narradores e que cintilam também em nós, fazendo durar imagens compartilhadas que se mesclam às nossas águas: as memórias e afetos próprios de cada um.

Sobre alguns contos, vamos prosear adiante, muito menos contando os conflitos geradores das histórias e os detalhes de seu desenvolvimento, mas muito mais nos deliciando no desenho da vida proposto pelo autor, escutador do mundo. Entre as narrativas, escolhemos apenas quatro delas para esta partilha, não tirando dos futuros leitores o direito ao espanto.

A narrativa que abre o livro e que também o nomeia conta sobre crianças com olhos lacrimejantes depois de um dia de sol e de mar. A poça de água nos olhos de uma criança que esqueceu de descer no ponto de ônibus correto. Esqueceu a vida? Quem sabe? Esqueceu de tanta vida? Quem sabe também? Talvez aqui o esquecimento foi tão doce que a poça dos olhos flui para os nossos olhos. Como não sentir, junto com o menino, o mar entre os dedos, banhando seu "corpo-ilha": "Cortou ondas, e riu, e boiou, e submergiu" (CARRASCOZA, 2018, p. 15). E, depois, como não se sentir perdido com o protagonista no conto que dá nome ao livro? “[...] aquela água toda pedia uma espera maior” (CARRASCOZA, 2018, p. 14). 
Outro conto lindíssimo, encenado nas páginas do livro, descreve a singeleza de um passeio. Um passeio em forma de mistério para um local que faz parte do imaginário das infâncias. Afinal, quem nunca se encantou ao ver um avião subindo ou pousando? Quem nunca imaginou os seres e vidas que riscam o céu com aquela máquina voadora? Quem nunca levou uma criança a olhar - simplesmente olhar - os aviões no aeroporto? Ou quem nunca se encantou ao contemplar as estrelas, a presença daqueles pontos em movimento nos lembrando que os aviões enxergam à noite e que hora ou outra eles se confundem com as estrelas? As delícias de um cotidiano abertas ao sabor, à escuta do mundo, seus instantes e águas do céu: Olha!

Entretanto, como no mundo da vida não figuram apenas belezas, de que forma não se emocionar com a paz roubada por uma fatura, um boleto, uma conta? Como não se emudecer juntamente com o protagonista diante de um solavanco, das mudanças de vozes em casa, de uma onda de medo e insegurança? Aquela água da louça lavando o silêncio de uma família diante dos sustos materiais que a vida nos dá. Como não ouvir aquele silêncio ensurdecedor de um nó na garganta? De uma lua triste: “O menino capturava a vida em hora instável" (CARRASCOZA, 2018, p. 84). As águas do silêncio pairam no ar do conto e no coração do menino.

E aqui chegamos a uma narrativa em que demoro mais, já que elaboro com ele relações mais profundas nos exercícios de leitura e escrita que venho me propondo com a escrita da tese.

Um dos contos narra uma saga que muitos de nós já vivemos ou já ajudamos alguém a viver. Narra, sob um ponto de vista único, o momento da retirada de um animalzinho morto de sua casa: o responsável que foi retirar o corpo de mais um cachorro que partira: “Aquela hora, do recolhimento, doía como uma lâmina enterrada para sempre na consciência" (CARRASCOZA, 2018, p. 47).

Em meus anos de docência, muitas vezes, a relação afetiva com os animais figurou nos textos e expressões dos estudantes. Foram instantes poéticos desenhados em contos, poemas, relatos de vida: narrativas contando o animalzinho amado que partiu depois de anos de convivência. Atropelamentos. Envenenamentos. Bezerros não sobreviventes ao vento do inverno. Essa vida que precisa se dobrar às intempéries. Foram vivências 
inusitadas de, por exemplo, encontrar um quero-quero no meio do caminho e não conseguir desviar dele e tal encontro se transformar numa peleja por continuar.

No meio do caminho tinha um quero-quero. Tinha um quero-quero no meio do caminho. Quando criança, havia muitos quero-queros no meu caminho para escola. Em algumas dessas vezes, tive de voltar para casa e chamar minha mãe para me ajudar a atravessar o mar tenebroso daqueles pássaros pernudos. Só mais velha, bem mais velha, já morando num bairro habitado pelos pássaros, fui descobrir que eram apenas mães protetoras cuidando de seus filhotes. Se soubesse antes, talvez tivesse lidado de forma diferente com o medo que sentia tão jovem e criança diante daquele desafio. Sempre tive medo de vacas e cachorros também, mas de quero-quero? Não era para tanto. Quem já viu a belezura dos filhotinhos pode entender o andar altivo das mamães. Elas sabem do valor daquelas perninhas lindas e longilíneas desfilando os primeiros passos pela relva.

O buraco da memória aqui desenhado serve para dizer que os bichos fazem parte de nossa história, de nossa formação e nos conectam com outras formas de vida, que tecem em nós outras compreensões sobre nossa humanidade. Os bichos fazem parte de nossa história e profundamente fazem parte do imaginário infantil, suas histórias, contos, sonhos, imagens. Muitas boas narrativas já foram contadas em variadas linguagens. Muitas águas já movimentaram ondas de sentido sobre os bichos.

Os bichos movimentam pensamentos, afetos, emoções. Os bichos dançam no baú de nossas imagens do coração. Aquelas que fazem bombear amor e poesia a nossos dias tão caros e prenhes de um olhar mais pausado e cuidadoso. Os bichos mexem com nossas águas límpidas e superficiais e também movimentam nossas águas mais profundas. Os bichos nos ensinam que as palavras são miúdas perto da indizibilidade da vida e do amor. Os bichos nos ensinam o quanto a incomunicação reina nas palavras humanas e suas tentativas de diálogos, de gagueiras, de violência.

Os bichos nos ensinam que é preciso ter calma diante do outro, deixá-lo se manifestar. Deixá-lo se aproximar. Deixá-lo também ir, quando necessário. Deixar também um silêncio de vez em quando no ar. Deixar que o silêncio fale um pouco por nós. Fale conosco. Deixar que o silêncio que temos diante de um bicho que não fala nossa língua nos incomode, nos atordoe, nos confunda. Afinal, andamos mesmo precisando nos banhar um pouco nas águas dos silêncios do mundo para melhor habitar a casa das palavras. Não 
aquelas palavras toscas e soltas ao vento pelas mídias, redes e mercados de capital. Mas palavras outras que possam permear de reinvenção as nossas relações com o mundo e com as pessoas.

No livro A Comunicação na educação, encharcado pela política pedagógica de Paulo Freire, Martín-Barbero (2014) admite que "falar não é apenas somente se servir de uma língua, mas pôr um mundo em comum, fazê-lo lugar de encontro" (p. 30). A demora com os bichos aqui tecida é para dizer o quanto os contos de Carrascoza (2018) nos capturam e abrem outros mundos a partir de uma imaginação tão rica em cenas poéticas do cotidiano. Há imagens encantadoras. Há cenas emudecedoras.

E de afeto em afeto, de imagem em imagem, temos aqui um "colar de pérolas", como uma vez escreveu o autor, para nos lembrar que há a poesia da vida que nos ajuda a seguir. Nos ajuda a escolher para onde lançamos nosso olhar de gente e de professor, o que, enfim, queremos escutar, valorizar, multiplicar, como cuidamos de nossos rios e de nossas águas secretas.

A vida multiplicada nos contos de Carrascoza (2018) é feita de sementes miúdas que guardam rios de poesia, de narrativas, de histórias e mais histórias para contar e escutar, nos ajudando a ler e escrever nossas próprias vidas, como quer Michele Petit (2013), bem como a ler e escrever nossos e outros mundos, como ensinou e continua ensinando Paulo Freire (1989, 2015). Os contos de Aquela água toda guardam mundos a serem compartilhados e celebrados nas comunidades narrativas de leitura e escrita pelo Brasil afora, alimentando memórias, presentes e sonhos de uma vida mais pausada e conectada com os nossos melhores afetos. 
BACHELARD, Gaston. O direito de Sonhar. $4^{\mathrm{a}}$ ed. Rio de Janeiro: Bertrand Brasil, 1994.

CARRASCOZA, João Anzanello. Aquela água toda. 1 $^{\text {a }}$ ed. Rio de Janeiro: Alfaguara, 2018.

CARRASCOZA, João Anzanello. Aos 7 e aos 40. $1^{\text {a }}$ edição. Rio de Janeiro: Alfaguara, 2016. Reimpresso em 2018.

GIRARDELLO, Gilka. Uma clareira no bosque: contar histórias na escola. Campinas, SP: Editora Papirus, 2014.

FREIRE, Paulo. A importância do ato de ler: em três artigos que se completam. São Paulo: Autores Associados; Cortez: 1989.

FREIRE, Paulo. Pedagogia da Indignação. Cartas pedagógicas e outros escritos. Organização e participação de Ana Maria de Araújo Freire. $2^{a}$ ed. São Paulo: Paz e Terra, 2015.

LABPUB. Entrevista: Aquela água toda. João A. Carrascoza. Blogue LabPub, publicada em 04 de março de 2020. Disponível em: https://www.labpub.com.br/aquela-agua-toda-joaoa-carrascoza/. Acesso em: 10 de abril de 2020.

PETIT, Michele. Leituras: do espaço íntimo ao espaço público. Tradução: Celina Olga de Souza. São Paulo: Editora 34, 2013

Universidade do Estado de Santa Catarina - UDESC Programa de Pós-Graduação em Educação - PPGE 